\title{
A distributed stream temperature model using high resolution temperature observations
}

\author{
M. C. Westhoff ${ }^{1}$, H. H. G. Savenije ${ }^{1}$, W. M. J . Luxemburg ${ }^{1}$, G. S. Stelling ${ }^{2}$, N. C. van de Giesen ${ }^{1}$, J. S. Selker ${ }^{3}$, \\ L. Pfister ${ }^{4}$, and S. Uhlenbrook ${ }^{5}$ \\ ${ }^{1}$ Water Resources Section, Faculty of Civil Engineering and Geosciences, Delft University of Technology, P.O. Box 5048, \\ 2600 GA Delft, The Netherlands \\ ${ }^{2}$ Fluid Mechanics Section, Faculty of Civil Engineering and Geosciences, Delft University of Technology, P.O. Box 5048, \\ 2600 GA Delft, The Netherlands \\ ${ }^{3}$ Department of Biological and Ecological Engineering, Oregon State University,116 Gilmore Hall, Corvallis, OR 97331, \\ USA \\ ${ }^{4}$ Department Environment and Agro-biotechnologies, Centre de Recherche Public - Gabriel Lippmann, 41, rue du Brill, 4422 \\ Belvaux, Luxembourg \\ ${ }^{5}$ Department of Water Engineering, UNESCO-IHE, Westvest 7, 2611 AX Delft, The Netherlands
}

Received: 18 December 2006 - Published in Hydrol. Earth Syst. Sci. Discuss.: 26 January 2007

Revised: 23 May 2007 - Accepted: 24 July 2007 - Published: 30 July 2007

\begin{abstract}
Distributed temperature data are used as input and as calibration data for an energy based temperature model of a first order stream in Luxembourg. A DTS (Distributed Temperature Sensing) system with a fiber optic cable of $1500 \mathrm{~m}$ was used to measure stream water temperature with $1 \mathrm{~m}$ resolution each $2 \mathrm{~min}$. Four groundwater inflows were identified and quantified (both temperature and relative discharge). The temperature model calculates the total energy balance including solar radiation (with shading effects), longwave radiation, latent heat, sensible heat and river bed conduction. The simulated temperature is compared with the observed temperature at all points along the stream. Knowledge of the lateral inflow appears to be crucial to simulate the temperature distribution and conversely, that stream temperature can be used successfully to identify sources of lateral inflow. The DTS fiber optic is an excellent tool to provide this knowledge.
\end{abstract}

\section{Introduction}

Rainfall runoff models are generally calibrated on discharge. However, successfully matching discharge does not mean that the internal processes in the catchment are modeled correctly. Seibert and McDonnell (2002) argued that rather than being "right for the wrong reasons," process representation in hydrological modeling would be better if it were "less right,

Correspondence to: M. C. Westhoff

(m.c.westhoff@tudelft.nl) for the right reasons." This is particularly of concern when models are desired to predict outflows under conditions that may not be well represented in the historical record, as is the case in many management and climate change contexts. If hydrological processes are understood better, models can be improved and parameters can be estimated better.

Tracers can be used to obtain a better insight in internal processes and possibly to separate hydrographs into different runoff components. Often isotopes such as deuterium (Wenninger et al., 2004), tritium or oxygen-18 (Sklash and Farvolden, 1979; Uhlenbrook and Leibundgut, 2002) are used to distinguish between event water and pre-event water. Besides these, dissolved silica and major ions (such as $\mathrm{Cl}^{-}$, $\mathrm{Na}^{+}, \mathrm{K}^{+}, \mathrm{Ca}^{+}$and $\mathrm{Mg}^{+}$) have been used, for a two, three or even a five component separation (Katsuyama et al., 2001; Kendall et al., 2001; Uhlenbrook and Hoeg, 2003).

Disadvantages of these tracers are varied: they can be expensive, difficult to analyze, and may not behave conservatively in the environment (e.g. ions). Temperature may also be used as a tracer. Kobayashi (1985), Shanley and Peters (1988) and Kobayashi et al. (1999) used temperature as a tracer, but did not determine the energy balance, which takes heating or cooling of the stream into account. Also, the transport processes of convection and dispersion were not taken into account. On the other hand, stream temperature models exist (Brown, 1969; Webb and Zhang, 1997; Evans et al., 1998; Boyd and Kasper, 2003) but they generally lack the capability to identify where and how much lateral inflow takes place. In the study presented here, the lateral inflow significantly influences the temperature of the stream, and is

Published by Copernicus Publications on behalf of the European Geosciences Union. 


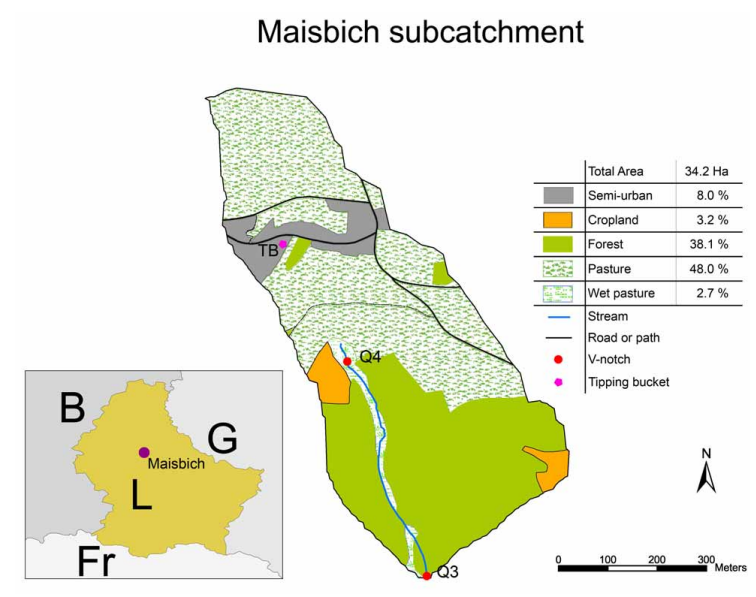

Fig. 1. Studied subcatchment of the Maisbich catchment. $\mathrm{B}=$ Belgium, $\mathrm{G}=$ Germany, $\mathrm{Fr}=$ France, $\mathrm{L}=$ Luxembourg.

therefore included in the study. Through temperature gauging we identify the quantity and location of lateral inflow (groundwater sources) to the stream.

Heat has been successfully employed to quantify groundwater contributions or losses to a stream (Stallman, 1965; Lapham, 1989; Silliman et al., 1995; Constantz, 1998; Constantz et al., 2003; Becker et al., 2004; Niswonger et al., 2005). Quantification of these fluxes requires measurements of temperatures at different depths in the stream bed. In our case the subsoil consists of schist which we could not penetrate. This study is different from previous work in that it only uses stream temperature observations to quantify lateral inflow.

We have developed an energy balance model that computes the temperature distribution along the stream taking into account lateral inflows and the primary energy flux terms. We use high resolution (in space and time) temperature measurements to calibrate the temperature model and, subsequently, to estimate the amount and location of lateral inflow. It is the first time that such high resolution data are used in a coupled hydrologic and energy balance model.

\section{Site description and measurements}

\subsection{Site description}

The study site is a subcatchment of the Maisbich catchment $\left(0.342 \mathrm{~km}^{2}\right.$; Fig. 1), located in central Luxemburg; latitude $49^{\circ} 53^{\prime} \mathrm{N}$ and longitude $6^{\circ} 02^{\prime} \mathrm{E}$. The subcatchment is the eastern branch of the Maisbich with elevations ranging from 296 to $494 \mathrm{~m}$.

The bedrock consists of schist covered with a soil layer. The upper part of the watershed is mainly pasture and some settlements. The stream begins with an assembly of seeps in a swampy vegetated hollow. Colluvial sediments are found on the surface.

Approximately $50 \mathrm{~m}$ downstream of the source a V-notch weir (Q4) has been installed. Another 50-100 m downstream the schist is exposed at the surface where both sides are steep forested slopes. Downstream of Q4 there are four distinct groundwater sources (Selker et al., 2006b), of which three sources could actually be observed in the field. It is likely that also diffuse exfiltration and infiltration will take place.

A V-notch weir (Q3) was installed at the confluence with a tributary at the downstream boundary of the watershed. The total length of the studied section between Q4 and Q3 is $580 \mathrm{~m}$. During the observation period the discharge was approximately constant $\left(1.21 \mathrm{~s}^{-1}\right.$ with a standard deviation of $0.141 \mathrm{~s}^{-1}$ at Q3). Precipitation was negligible during the experiment (the total precipitation over the period considered amounted to $2 \mathrm{~mm}$ in 7 days. The maximum intensity was $0.8 \mathrm{~mm}$ in ten minutes).

\subsection{Measurements}

The downstream discharge was measured at Q3 at $10 \mathrm{~min}$ intervals using a pressure sensor (Keller DCX22). At Q4 hand measurements were taken at 2-5-2006 09:30, 14:40 and 15:30 and at 3-5-2006 10:43 and 11:58. The precipitation was measured by a tipping bucket recording rain gauge (TB in Fig. 1). The water temperature was measured with a DTS (Distributed Temperature Sensing) fiber optic cable (BRUsens, Brugg, Switzerland) using the Sensornet system (Sentinel DTS-LR, London, England). It measures the temperature with a precision of $0.01^{\circ} \mathrm{C}$ (integrated over $30 \mathrm{~min}$ ) and a spatial resolution of $1 \mathrm{~m}$. Every two minutes a longitudinal temperature profile was stored. For a detailed description see Selker et al. (2006a).

Air temperature and relative humidity were measured at Ettelbruck (ca. $7 \mathrm{~km}$ from the catchment at an elevation of $253 \mathrm{~m}$ in open field, by the Administration des Services Techniques de l'Agriculture, Luxembourg) at $10 \mathrm{~min}$ intervals. There was no meteorological data taken within the catchment at the time of the study. As no reliable wind velocities (necessary for estimating the evaporation) were measured, a wind velocity of $0.1 \mathrm{~m} \mathrm{~s}^{-1}$ is taken as an assumed value for the whole period. This value reflects that no wind was noticed in the field. Solar radiation was estimated using satellite data from LandSAF (Land Surface Analysis Satellite Applications Facility; http://landsaf.meteo.pt), with $3 \mathrm{~km}$ by $3 \mathrm{~km}$ resolution. In subsequent studies we shall use a local station. For the purpose of this paper the possible error introduced is small since it may only effect the energy balance to a minor extend (see Sect. 5) and will not affect the quantification of lateral inflows. 


\section{Methods}

\subsection{Model description}

The temperature model is based on a system of well mixed "reservoirs" with a length of $2 \mathrm{~m}$. A first order upwind scheme is used. To minimize the nummerical diffusion the Van Leer limiter (Van Leer, 1974) is used. The limiter is a kind of anti-diffusion, that reduces the nummerical diffusion of the upwinding, while keeping positive solutions. This is done by estimating the stream temperature at the downstream border of each section in a non-linear way. For each section, the net energy is added. Dispersion of heat between two "reservoirs" is assumed to be negligible within the accuracy of the model. The mass and energy balance for temperature transport are:

$$
\begin{aligned}
& \frac{\partial A}{\partial t}+\frac{\partial Q}{\partial x}=q_{L} \\
& \frac{\partial(A T)}{\partial t}+\frac{\partial(Q T)}{\partial x}=q_{L} T_{L}+R \\
& R=\frac{B \Phi_{\text {total }}}{\rho_{w} c_{w}}
\end{aligned}
$$

where $Q, A$ and $T$ are the discharge $\left[\mathrm{m}^{3} \mathrm{~s}^{-1}\right]$, the cross sectional area $\left[\mathrm{m}^{2}\right]$ and the water temperature $\left[{ }^{\circ} \mathrm{C}\right] . q_{L}$ is the lateral inflow per unit width $\left[\mathrm{m}^{2} \mathrm{~s}^{-1}\right]$ and $T_{L}$ is the temperature of lateral inflow. $R$ is the sink/source term (Boderie and Dardengo, 2003), where $\Phi_{\text {total }}$ is the sum of all the energy fluxes per unit area $\left[\mathrm{W} \mathrm{m}^{-2}\right], B$ is the width $[\mathrm{m}]$ of the section, $\rho_{w}$ is the density $\left[\mathrm{kg} \mathrm{m}^{-3}\right]$ of water and $c_{w}$ is the specific heat capacity $\left[\mathrm{J} \mathrm{kg}^{-1}{ }^{\circ} \mathrm{C}^{-1}\right]$ of water. $\partial / \partial t$ and $\partial / \partial x$ are the derivatives to time $\left[\mathrm{s}^{-1}\right]$ and space $\left[\mathrm{m}^{-1}\right]$. In finite volumes Eqs. (1) and (2) become:

$\frac{\mathrm{d} V_{i}}{\mathrm{~d} t}=Q_{i-\frac{1}{2}}-Q_{i+\frac{1}{2}}+Q_{L}$

$\frac{\mathrm{d}\left(V_{i} T_{i}\right)}{\mathrm{d} t}=Q_{i-\frac{1}{2}} T_{i-\frac{1}{2}}-Q_{i+\frac{1}{2}} T_{i+\frac{1}{2}}+Q_{L} T_{L}+\frac{R_{i} V_{i}}{A_{i}}$

where $V_{i}$ is the volume $\left[\mathrm{m}^{3}\right]$ and $A_{i}$ is the cross sectional area $\left[\mathrm{m}^{2}\right]$ of section $i . T_{i}$ is the water temperature of section i. $Q_{i-\frac{1}{2}}$ and $Q_{i+\frac{1}{2}}$ are the water fluxes between section $i$ and the upstream and downstream section respectively. $Q_{L}$ is the lateral inflow $\left[\mathrm{m}^{3} \mathrm{~s}^{-1}\right]$ and $T_{i-\frac{1}{2}}$ and $T_{i+\frac{1}{2}}$ are the upstream and downstream temperatures of section $i$. For $\mathrm{Q}>0$, they are given by:

$T_{i-\frac{1}{2}}=T_{i-1}+\Delta T_{i-1}$

$T_{i+\frac{1}{2}}=T_{i}+\Delta T_{i}$

where $\Delta T_{i-1}$ and $\Delta T_{i}$ are the temperature gradients between section $i$ and the downstream and upstream section, respectively. They are given by (Van Leer, 1974):

$\Delta T_{i-1}=\frac{\max \left(0, \Delta^{+} T_{i-1} \cdot \Delta^{-} T_{i-1}\right)}{\Delta^{+} T_{i-1}+\Delta^{-} T_{i-1}}$
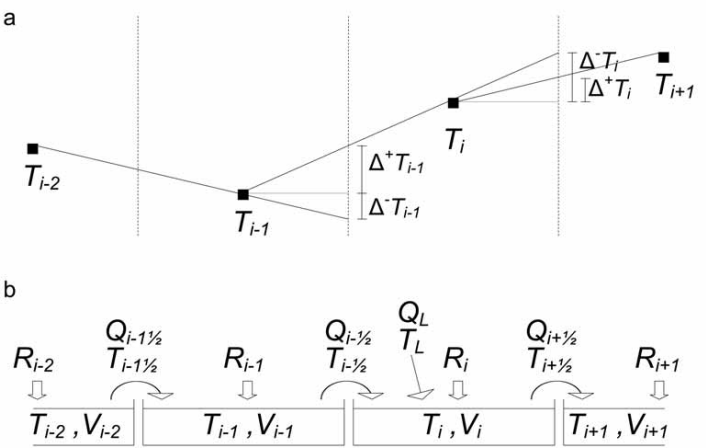

Fig. 2. (a) Visualisation of $\Delta^{+} T_{i-1}, \Delta^{-} T_{i-1}, \Delta^{+} T_{i}$ and $\Delta^{-} T_{i}$. (b) Conceptual sketch of the temperature model. All discharge terms $(Q)$ and all volumes $(V)$ are taken to be constant over time. All temperature $(T)$ and energy flux $(R)$ terms fluctuate over time

$\Delta T_{i}=\frac{\max \left(0, \Delta^{+} T_{i} \cdot \Delta^{-} T_{i}\right)}{\Delta^{+} T_{i}+\Delta^{-} T_{i}}$

where $\Delta^{+} T_{i-1}$ and $\Delta^{-} T_{i-1}$ are the interpolated and extrapolated gradients of the downstream and upstream node of section $i-1$ while $\Delta^{+} T_{i}$ and $\Delta^{-} T_{i}$ are the interpolated and extrapolated gradients of the downstream and upstream node of section $i$ (Fig. 2a). Combining Eqs. (4) to (7) yields (Fig. 2b):

$$
\frac{\mathrm{d} T_{i}}{\mathrm{~d} t}=\frac{Q_{i-\frac{1}{2}}\left(T_{i-1}-T_{i}\right)}{V_{i}}+\frac{Q_{i-\frac{1}{2}} \Delta T_{i-1}-Q_{i+\frac{1}{2}} \Delta T_{i}}{V_{i}}
$$

where the first term is the first-order upwind and the second term is the anti-diffusion term. Integration in time is done with a Lax-Wendroff type of time integration.

\subsection{Energy balance}

The model takes the following energy fluxes into account: Solar radiation (including shading effects) $\left(\Phi_{\text {solar }}\right)$, longwave radiation $\left(\Phi_{\text {longwave }}\right)$, streambed conduction $\left(\Phi_{\text {conduction }}\right)$, latent heat $\left(\Phi_{\text {evaporation }}\right)$, and sensible heat $\left(\Phi_{\text {sensible_heat }}\right)$.

\subsubsection{Solar radiation}

Solar radiation consists of direct radiation and diffuse radiation. Shadowing influences the direct radiation, and thus must be estimated. Critical shadow angles were calculated for each grid cell. Partial shading due to vegetation was also taken into account. The diffuse radiation is not influenced by shadows. The solar radiation is computed as:

$$
\begin{aligned}
& \Phi_{\text {solar }}=\left(1-D_{f}\right)\left(\Phi_{\text {direct }}+\Phi_{\text {diffuse }}\right) \\
& \Phi_{\text {direct }}=C_{s}\left(1-D_{\text {diffuse }}\right) \Phi_{\text {Landsaf }}
\end{aligned}
$$


$\Phi_{\text {diffuse }}=D_{\text {diffuse }} \Phi_{\text {Landsaf }}$

where $\Phi_{\text {direct }}$ is the direct solar radiation compensated for shadow effects (factor $C_{S}[-]$ ). $\Phi_{\text {Landsaf }}$ is the solar radiation measured by the LandSAF satellite. $D_{f}$ is the fraction [-] of solar radiation which reaches (warms up) the stream bed (and which is not used for warming up the water directly). $\Phi_{\text {diffuse }}$ is the diffuse solar radiation, and $D_{\text {diffuse }}$ is the fraction [-] of solar energy which is diffuse.

The factor $C_{s}$ was determined by looking at thresholds for shading depending on topographic and vegetation angles, using TTools, developed by Boyd and Kasper (2003) as an Arcview GIS extension. The topographic angle for each grid cell was determined in three directions (east, south and west) with a digital elevation model (DEM). When the sun is below the topographic angle, $C_{s}=0$, and when there is no shading $C_{s}=1$. Six different vegetation classes were defined representing different heights and densities of vegetation. The threshold angles are determined in seven directions (northeast, north, southeast, south, southwest, west and northwest).

\subsubsection{Longwave radiation}

Longwave radiation includes the atmospheric longwave radiation, back radiation (radiation flux emitted from the water column) and land cover longwave radiation. They are all calculated using the Stefan-Boltzman law.

Atmospheric longwave radiation is the longwave radiation the water receives from the atmosphere. It is computed as (Boderie and Dardengo, 2003):

$$
\begin{aligned}
& \Phi_{\text {atmospheric }}=0.96 \varepsilon_{\mathrm{atm}} \sigma_{s b}\left(T_{\mathrm{air}}+273.2\right)^{4} \\
& \varepsilon_{\mathrm{atm}}=1.1 B_{c}+a_{1} \sqrt{e_{a}} \\
& e_{s}=0.61275 e^{\left(\frac{17.27 T_{\mathrm{air}}}{237.3+T_{\mathrm{air}}}\right)} \\
& e_{a}=\frac{H}{100 \%} e_{s}
\end{aligned}
$$

where $T_{\text {air }}$ is the air temperature $\left[{ }^{\circ} \mathrm{C}\right], \varepsilon_{\mathrm{atm}}$ is the emissivity of the atmosphere $[-], a_{1}$ is an empirical constant $\left[(\mathrm{kPa})^{-0.5}\right]$ and $\sigma_{s b}$ is the Stefan-Boltzman constant $\left[\mathrm{W} \mathrm{m}^{-2}{ }^{\circ} \mathrm{C}^{-4}\right] . H$ is the relative humidity [-], $e_{a}$ is the actual vapour pressure $[\mathrm{kPa}], e_{s}$ is the saturation vapour pressure $[\mathrm{kPa}]$ and $B_{c}$ is the "Brunt" coefficient [-], which is a function of air temperature and the ratio of measured solar radiation and calculated clear sky radiation (Boderie and Dardengo, 2003).

Back radiation is the energy flux emitted from the water column. It is computed as (Boyd and Kasper, 2003):

$\Phi_{\text {back_radiation }}=-0.96 \sigma_{s b}(T+273.2)^{4}$

Land cover longwave radiation is the longwave radiation emitted by the vergetation and received by the water. If vegetation is denser more radiation is emitted to the stream. This is expressed in the "view to sky" coefficient. The land cover longwave radiation is computed as (Boyd and Kasper, 2003):

$\Phi_{\text {land_cover }}=0.96\left(1-\theta_{\mathrm{VTS}}\right) 0.96 \sigma_{s b}\left(T_{\text {air }}+273.2\right)^{4}$

where $\theta_{\mathrm{VTS}}$ is the "view to sky" coefficient [-].

\subsubsection{Streambed conduction}

Heat energy transfer between the water and the riverbed is called streambed conduction. It is driven by temperature differences between the water and the substrate layer. The substrate layer is represented as a layer which is also influenced by energy fluxes. It is a layer placed between the water and the deeper alluvium. The latter is assumed to have a constant temperature. Conduction is computed as (Boyd and Kasper, 2003), assuming that the river bed is saturated:

$$
\begin{aligned}
& \Phi_{\text {conduction }}=-K_{\text {soil }} \frac{T-T_{\text {soil }}}{d_{\text {soil }}} \\
& T_{\text {soil }}^{t+1}=T_{\text {soil }}^{t}+\Delta T_{\text {soil }} \\
& \Delta T_{\text {soil }}=\Phi_{\text {net }} \frac{\Delta t}{d_{\text {soil }} \rho_{\text {soil }} c_{\text {soil }}} \\
& \Phi_{\text {net }}=\left(\Phi_{\text {solar }} \frac{D f}{1-D f}-\Phi_{\text {conduction }}+\Phi_{\text {conduction }}^{\text {alluvium }}\right) \\
& \Phi_{\text {conduction }}^{\text {alluvium }}=-K_{\text {soil }} \frac{T_{\text {soil }}-T_{\text {alluvium }}}{d_{\text {soil }}} \\
& K_{\text {soil }}=K_{\text {sed }}(1-\eta)+K_{w} \eta \\
& \rho_{\text {soil }}=\rho_{\text {sed }}(1-\eta)+\rho_{w} \eta \\
& c_{\text {soil }}=c_{\text {sed }}(1-\eta)+c_{w} \eta
\end{aligned}
$$

where $K_{\text {soil }}$ is the volumetric weighted thermal conductivity $\left[\mathrm{J} \mathrm{m}^{-1} \mathrm{~s}^{-1}{ }^{\circ} \mathrm{C}^{-1}\right], T_{\text {soil }}, \rho_{\text {soil }}$ and $c_{\text {soil }}$ are the temperature, density and specific heat capacity of the substrate layer. $K_{\text {sed }}$ and $K_{w}$ are the thermal conductivity $\left[\mathrm{J} \mathrm{m}^{-1} \mathrm{~s}^{-1}{ }^{\circ} \mathrm{C}^{-1}\right.$ ] of the sediment and the water. $\rho_{\text {sed }}$ and $c_{\text {sed }}$ are the density and the specific heat capacity of the sediment. $T_{\text {alluvium }}$ is the temperature of the deeper alluvium, $\eta$ is the porosity [-] of the substrate layer and $\Delta t$ is the time step [s].

\subsubsection{Latent heat flux}

Latent heat is the energy used for evaporation. It is computed using the Penman equation for open water (Monteith, 1981):

$$
\begin{aligned}
& \Phi_{\text {evaporation }}=-\rho_{w} L_{e} E \\
& L_{e}=1000(2501.4+T) \\
& E=\frac{s \Phi_{r}}{\rho_{w} L_{e}(s+\gamma)}+\frac{c_{\mathrm{air}} \rho_{\mathrm{air}}\left(e_{s}-e_{a}\right)}{\rho_{w} L_{e} r_{a}(s+\gamma)}
\end{aligned}
$$


$s=\frac{4100 e_{s}}{\left(237+T_{\mathrm{air}}\right)^{2}}$

$r_{a}=\frac{245}{0.54 v_{\text {wind }}+0.5}$

where $L_{e}$ is the latent heat of vaporation $\left[\mathrm{J} \mathrm{kg}^{-1}\right]$ and $E$ is the Penman open water evaporation $\left[\mathrm{m} \mathrm{s}^{-1}\right] . \Phi_{r}$ is the net radiation $\left[\mathrm{W} \mathrm{m}^{-2}\right.$, which is the sum of the solar radiation and longwave radiation. $s$ is the slope of the saturated vapour pressure curve at a given air temperature $\left[\mathrm{kPa}^{\circ} \mathrm{C}^{-1}\right], \gamma$ is the psychrometric constant $\left[\mathrm{kPa}^{\circ} \mathrm{C}^{-1}\right], r_{a}$ is the aerodynamic resistance $\left[\mathrm{s} \mathrm{m}^{-1}\right]$, and $v_{\text {wind }}$ is the wind speed $\left[\mathrm{m} \mathrm{s}^{-1}\right] . c_{\text {air }}$ and $\rho_{\text {air }}$ are the specific heat capacity and the density of air.

\subsubsection{Sensible heat flux}

The sensible heat flux is the heat exchange between the water and the air, which is driven by temperature differences. It is computed as (Boyd and Kasper, 2003):

$\Phi_{\text {sensible_heat }}=B_{r} \Phi_{\text {evaporation }}$

$B_{r}=6.1 \cdot 10^{-4} P_{A} \frac{T-T_{\text {air }}}{e_{s}^{w}-e_{a}^{w}}$

$e_{s}^{w}=0.61275 e^{\left(\frac{17.27 T}{237.3+T}\right)}$

$e_{a}^{w}=\frac{H}{100 \%} e_{s}^{w}$

$P_{A}=101.3-0.01055 z$

where $B_{r}$ is the Bowen Ratio [-], $e_{s}^{w}$ and $e_{a}^{w}$ are the saturated and actual vapour pressure $[\mathrm{kPa}]$ using the stream temperature, $P_{A}$ is the adiabatic atmospheric pressure $[\mathrm{kPa}]$, and $z$ is the elevation $[\mathrm{m}]$ at which humidity and air temperature were measured.

The energy balance model requires a great deal of data. In our study the constants $D_{f}, D_{\text {diffuse }}, \theta$ VTS, and $d_{\text {soil }}$ were obtained through calibration. The other parameters were measured or fixed to a value found in the literature (Table 1).

\subsection{Determination of lateral inflow}

To compute the lateral inflow of single sources the mass and heat conservation equations are used (Kobayashi, 1985; Selker et al., 2006b):

$Q_{d}=Q_{u}+Q_{L}$

$T_{d} Q_{d}=T_{u} Q_{u}+T_{L} Q_{L}$

where $Q$ is discharge $\left[\mathrm{m}^{3} \mathrm{~s}^{-1}\right], T$ is the water temperature and the subscripts $d, u$ and $L$ are downstream, upstream and lateral inflow, respectively. The ratio between $Q_{L}$ and $Q_{d}$ can be derived by solving Eqs. (38) and (39):

$\frac{Q_{L}}{Q_{d}}=\frac{T_{d}-T_{u}}{T_{L}-T_{u}}$ where $T_{L}$ is still unknown. Due to the fact that the subsoil consists of schist it is very difficult to measure the temperature of the lateral inflows. The groundwater flows through cracks and fissures before it enters the stream. At these points it is not clear to what extent the groundwater is already mixed with the stream water. Therefore we used the following two methods to determine the temperature of the lateral inflow described by Selker et al. (2006b):

1. In our study the stream temperature was both above and below the groundwater temperature. At the moment when there is no change in the longitudinal temperature profile at the point of a groundwater inflow, the temperature of the groundwater source may be taken to be the same as the measured upstream and downstream temperature.

2. $T_{L}$ can be derived from two profiles at different times. The assumptions are that $Q_{L} / Q_{d}$ and $T_{L}$ are constant over the time between the two series. Using Eq. (40) for two profiles will result in:

$\frac{T_{d_{1}}-T_{u_{1}}}{T_{L}-T_{u_{1}}}=\frac{T_{d_{2}}-T_{u_{2}}}{T_{L}-T_{u_{2}}}$

and hence

$T_{L}=\frac{T_{d_{2}} T_{u_{1}}-T_{u_{2}} T_{d_{1}}}{T_{d_{2}}-T_{u_{2}}-T_{d_{1}}+T_{u_{1}}}$

where the subscripts 1 and 2 relate to the two profiles. $Q_{L} / Q_{d}$ can also be calculated directly from two profiles using Eq. (40).

$$
\frac{Q_{L}}{Q_{d}}=\frac{T_{d_{2}}-T_{u_{2}}-T_{d_{1}}+T_{u_{1}}}{T_{u_{1}}-T_{u_{2}}}
$$

Equation (43) makes it straightforward to determine the accuracy of temperature measurements, required to determine the lateral inflows as a fraction of the incoming flow. This calculation is important as in this method large errors can occur in the derivation of $Q_{L} / Q_{d}$, due the propagation of errors in the process of subtracting. The relative error $r$ is given by:

$$
\begin{aligned}
r_{\left(\frac{Q_{L}}{Q_{d}}\right)}^{2}= & \frac{\sigma_{\left(T_{d_{2}}\right)}^{2}+\sigma_{\left(T_{u_{1}}\right)}^{2}+\sigma_{\left(T_{u_{2}}\right)}^{2}+\sigma_{\left(T_{d_{1}}\right)}^{2}}{\left(T_{d_{2}}-T_{d_{1}}+T_{u_{1}}-T_{u_{2}}\right)^{2}} \\
& +\frac{\sigma_{\left(T_{u_{1}}\right)}^{2}+\sigma_{\left(T_{u_{2}}\right)}^{2}}{\left(T_{u_{1}}-T_{u_{2}}\right)^{2}}
\end{aligned}
$$

where $\sigma$ is the standard deviation of the measured temperature. In principle any combination of profiles may be employed in this calculation. If two profiles are close in temperature or if the jump in one profile is small, large errors can occur. We estimated $T_{L}$ and $Q_{L} / Q_{d}$ by computing the average of the values obtained within a $16 \mathrm{~h}$ period that had a relative error less than $10 \%$. The standard deviation and the coefficients of variance $\left(C_{V}=\sigma / \mu\right)$ were calculated to define the accuracy of $T_{L}$ and $Q_{L} / Q_{d}$ (Table 2). 
Table 1. Constants and parameters used in the model. If a parameter is time or place dependent, the minimum and maximum values are given. All other parameters are assumed to be time and place independent. The sensitivity is defined as the relative change in the Root Mean Square Error (RMSE) subject to a relative change in the parameter in question. The variation used for each parameter is $10 \%$. In case a parameters is a time series (e.g. air temperature) the whole time series was increased/decreased. Where an increase or decrease of a parameter demonstrate a different sensitivity, the maximum value is given. On physical constants no sensitivity analysis has been performed. The initial RMSE was 1.01 .

\begin{tabular}{|c|c|c|c|c|}
\hline Constant & Description & Value & Reference & Sensitivity \\
\hline$D_{f}[-]$ & $\begin{array}{l}\text { Fraction of solar radiation } \\
\text { reaching the streambed }\end{array}$ & 0.5 & Calibrated & 0.78 \\
\hline$D_{\text {diffuse }}[-]$ & Fraction of diffuse solar radiation & 0.3 & Calibrated & 0.11 \\
\hline$\theta_{\mathrm{VTS}}[-]$ & View to the sky coefficient & 0.9 & Calibrated & 1.14 \\
\hline$d_{\text {soil }}[\mathrm{m}]$ & Thickness of substrate layer & 0.071 & Calibrated & 0.09 \\
\hline$\sigma_{s b}\left[\mathrm{~W} \mathrm{~m}^{-2}{ }^{\circ} \mathrm{C}^{-1}\right]$ & Stefan-Boltzman constant & $5.67 \cdot 10^{-8}$ & Evans et al. (1998) & \\
\hline$\gamma\left[\mathrm{kPa}^{\circ} \mathrm{C}^{-1}\right]$ & Psychrometric constant & 0.66 & Dingman (2002) & \\
\hline$\rho_{w}\left[\mathrm{~kg} \mathrm{~m}^{-3}\right]$ & Density of water & 1000 & Boyd and Kasper (2003) & \\
\hline$\rho_{\text {sed }}\left[\mathrm{kg} \mathrm{m}^{-3}\right]$ & Density of sediment & 1600 & Boyd and Kasper (2003) & \\
\hline$\rho_{\text {air }}\left[\mathrm{kg} \mathrm{m}^{-3}\right]$ & Denstity of air & 1.2 & Williams (2006) & \\
\hline$c_{w}\left[\mathrm{~J} \mathrm{~kg}^{-1}{ }^{\circ} \mathrm{C}^{-1}\right]$ & Specific heat capacity of water & 4182 & Boyd and Kasper (2003) & \\
\hline$c_{\text {sed }}\left[\mathrm{J} \mathrm{kg}^{-1}{ }^{\circ} \mathrm{C}^{-1}\right]$ & Specific heat capacity of the sediment & 2219 & Boyd and Kasper (2003) & \\
\hline$c_{\text {air }}\left[\mathrm{J} \mathrm{kg}^{-1}{ }^{\circ} \mathrm{C}^{-1}\right]$ & Specific heat capacity of air & 1004 & Dingman (2002) & \\
\hline$K_{w}\left[\mathrm{~W} \mathrm{~m}^{-1}{ }^{\circ} \mathrm{C}^{-1}\right]$ & Thermal conductivity of water & 0.6 & Boyd and Kasper (2003) & \\
\hline$K_{\text {sed }}\left[\mathrm{W} \mathrm{m}^{-1}{ }^{\circ} \mathrm{C}^{-1}\right]$ & Thermal conductivity of the sediment & 3.4 & Shi et al. (1996) & \\
\hline$\eta[-]$ & Porosity & 0.3 & Estimated & 0.01 \\
\hline$a_{1}\left[(\mathrm{kPa})^{-0.5}\right]$ & Empirical constant in Eq. (15) & 0.094 & Boderie and Dardengo (2003) & \\
\hline$B_{c}[-]$ & Brunt coefficient & $0.6-0.7$ & Boderie and Dardengo (2003) & 0.69 \\
\hline$C_{S}[-]$ & Shadow factor & $0-1$ & Estimated & \\
\hline$T_{\text {air }}\left[{ }^{\circ} \mathrm{C}\right]$ & Air temperature & $1.9-24.1$ & Measured & 0.34 \\
\hline$H[-]$ & Humidity & $18-90 \%$ & Measured & 0.03 \\
\hline$\Phi_{\text {Landsaf }}\left[\mathrm{W} \mathrm{m}^{-2}\right]$ & Solar radiation & $0-860$ & Measured & 0.38 \\
\hline$v_{\text {wind }}\left[\mathrm{m} \mathrm{s}^{-1}\right]$ & Wind velocity & 0.1 & Estimated & $0.11^{*}$ \\
\hline$d t[\mathrm{~s}]$ & Time step & 10 & Chosen & \\
\hline$d x[\mathrm{~m}]$ & Length of reservoir & 2 & Chosen & \\
\hline$A\left[\mathrm{~m}^{2}\right]$ & Cross section of a reservoir & $0.0054-0.0449$ & Estimated & \\
\hline$V\left[\mathrm{~m}^{3}\right]$ & Volume of a reservoir & $0.0108-0.0569$ & Estimated & \\
\hline$T_{\text {alluvium }}\left[{ }^{\circ} \mathrm{C}\right]$ & Temperature of the alluvium & 9 & Estimated & 0.38 \\
\hline$z[\mathrm{~m}]$ & Elevation height & 2 & Estimated & 0.00 \\
\hline
\end{tabular}

*A wind velocity of $1 \mathrm{~m} \mathrm{~s}^{-1}$ is taken to determine the change in the RMSE.

\subsection{Assumptions and limitations}

Several assumptions have been made which merit being made explicit. Regarding the lateral inflow determination in Eqs. (42) and (43), the assumption is made that over the time interval between the two profiles $T_{L}$ and $Q_{L} / Q_{d}$ are constant. The observed small coefficients of variance of $T_{L}$ and $Q_{L} / Q_{d}$ (Table 2) and the fact that the upstream and downstream temperature of the sources intersect eachother at a constant temperature (see Sect. 4) suggest that this assumption is valid .

In cases where $T_{L}$ and $Q_{L} / Q_{d}$ are not constant between two considered profiles in time, $T_{L}$ should be determined in an alternative way after which it can be used in Eq. (40).

The determination of $T_{L}$ and $Q_{L} / Q_{d}$ with temperature measurements can be done only if the lateral inflow significantly alters the stream water temperature. If this is not the case, the relative error calculated with Eq. (44) will become large. This method is not suitable if the mixing-length is so large that heat fluxes are no longer small compared to the temperature change due to the groundwater input. This also assumes that the temperature over the cross-section of the stream is constant.

Regarding Eq. (10), the assumption is made that the discharge is constant over time and spatially varies only due to groundwater sources. This implies constant stream velocity and constant volume of each modeled reservoir over time. This is an acceptable assumption in this study since the observed discharge shows a very small variation around the average $\left(\sigma=0.141 \mathrm{~s}^{-1}\right)$. Because the discharge can be taken as a 
Table 2. Calculated temperature and relative contributions of the four sources. Point 1 is the most upstream source and point 4 the most downstream.

\begin{tabular}{|c|c|c|c|c|c|c|c|}
\hline inflow & {$\left[{ }^{\circ} \mathrm{C}\right]$} & {$\left[{ }^{\circ} \mathrm{C}\right]$} & $\begin{array}{l}Q_{L} / Q_{d} \\
{[\%]}\end{array}$ & $\begin{array}{l}\sigma_{\left(T_{L}\right)}^{2} \\
{\left[{ }^{\circ} \mathrm{C}\right]}\end{array}$ & $\begin{array}{l}\sigma_{\left(\frac{Q_{L}}{Q_{d}}\right)} \\
{[\%]}\end{array}$ & $\begin{array}{l}C_{V_{\left(T_{L}\right)}} \\
{[-]}\end{array}$ & ${ }_{[-]}^{C_{V}}\left(\frac{Q_{L}}{Q_{d}}\right)$ \\
\hline 1 & 9.08 & 9.11 & 58.5 & 0.37 & 7.89 & 0.04 & 0.13 \\
\hline 2 & 8.70 & 8.85 & 30.0 & 0.23 & 4.27 & 0.03 & 0.14 \\
\hline 3 & 8.77 & 8.91 & 15.2 & 0.22 & 0.87 & 0.02 & 0.06 \\
\hline 4 & 8.44 & 8.18 & 22.8 & 0.24 & 2.6 & 0.03 & 0.11 \\
\hline
\end{tabular}

* Temperature of lateral inflow calculated when no jumps are seen. (From Selker et al., 2006b).

constant, and because the stream is very small and turbulent, the stream can be suitably modeled as a system of well mixed reservoirs which all have a rectangular channel geometry.

The model does not account for diffuse sources or losses of water. Although there is reason to believe that there are diffuse sources (e.g. Selker et al., 2006b), no data has been gathered which could identify the distribution of such processes. Because the groundwater at this site flows primarily through cracks, point sources are thought to be dominant at this site in comparison to diffuse sources.

Another assumption is that the deeper alluvium has approximately the same temperature as the groundwater $\left(T_{\text {alluvium }} \approx T_{L}\right)$. As long as no stream water infiltrates, the temperature of the groundwater can be considered constant over a short period. Only when water infiltrates, the deeper alluvium will be influenced by the stream water temperature (e.g. Constantz et al., 2003). The "view to the sky" coefficient is, as yet, considered constant along the stream and the observed air temperature and relative humidity of a nearby station are considered representative for the study site.

\section{Results}

Four sources can be distinguished along the monitored reach (Fig. 3). Beyond the influence of groundwater inflows, large fluctuations in temperature (in time as well as in space) are observed due to changing climatic conditions. Localized anomalies in temperature occur where the cable is out of the water (e.g. at a small water fall at $404 \mathrm{~m}$ ). At 06:00 a.m. the first two sources cause warming up of the stream while later in the day temperature drops occur at these places.

The small coefficients of variance of $T_{L}$ (Table 2) indicate that the temperature of the sources are constant over time. This also means that the upstream and downstream temperature of the sources intersect always at the same temperature (Fig. 4a). The difference between the computed temperature of a source using the two different methods is always less than $0.15^{\circ} \mathrm{C}$ for the first three sources and $0.26^{\circ} \mathrm{C}$ for source 4 (Table 2). For source 4 this is equal to the standard de- viation of $T_{L}$, while for the first three sources this is even smaller than the standard deviation.

The differences between $T_{L}^{*}\left(T_{L}\right.$ determined by method 1$)$ and $T_{L}\left(T_{L}\right.$ determined by method 2, Eq. 42$)$ may have occurred because $T_{L}^{*}$ is always determined in relatively cold circumstances, while the other method is based on daily average temperature which is subject to different sensitivity to environmental conditions. For the temperature model (Eq. 10) $T_{L}$ and $Q_{L} / Q_{d}$ have been determined by Eqs. (42) and (43). Using a discharge of $1.21 \mathrm{~s}^{-1}$ at $\mathrm{Q} 3$, the absolute contributions of the four sources are: $0.33,0.24,0.15$ and $0.281 \mathrm{~s}^{-1}$, respectively.

Calibration consisted of minimizing the Root Mean Square Error (RMSE) by varying the four adjustable parameters $D_{f}, D_{\text {diffuse }}, \theta_{\mathrm{VTS}}$, and $d_{\text {soil }}$ (Table 1 ). Sensitivity has been evaluated by recomputing the RMSE using parameter values $10 \%$ above and $10 \%$ below the optimized values, presented as the relative change in RMSE per relative change of the parameter. The most sensitive parameters are $D_{f}$, the "view to the sky" coefficient $\left(\theta_{\mathrm{VTS}}\right)$ and the Brunt coefficient $\left(B_{c}\right)$, with a sensitivity of $0.78,1.14$ and 0.69 , respectively (Table 1).

The simulation period spans 23 April 2006 15:00 through 30 April 2006 00:00 (Fig. 4). The source at $110 \mathrm{~m}$ has a clear influence on the daily maxima, while the daily minima remain essentially unchanged since the source temperature is closer to the minima than the maxima. The influence of the multiple groundwater sources on the stream temperature can be clearly seen in the longitudinal temperature profiles (Fig. 5). When the temperature is more or less constant over the length (Fig. 5a) the simulated temperature matches the observed temperature very well. When the spatial variability is high, the model performance diminishes (Fig. 5b-d), especially when the slope of the temperature profile is negative (water gets colder downstream). We suspect that this is due to the presence of unmodeled diffuse sources (e.g. Fig. 5b, from 70 to $100 \mathrm{~m}$ ).

Solar radiation is the main flux responsible for the daily temperature variation (Fig. 6). Conduction has a damping effect on the water temperature. During the day, conduction functions as an energy sink, while during the night it 


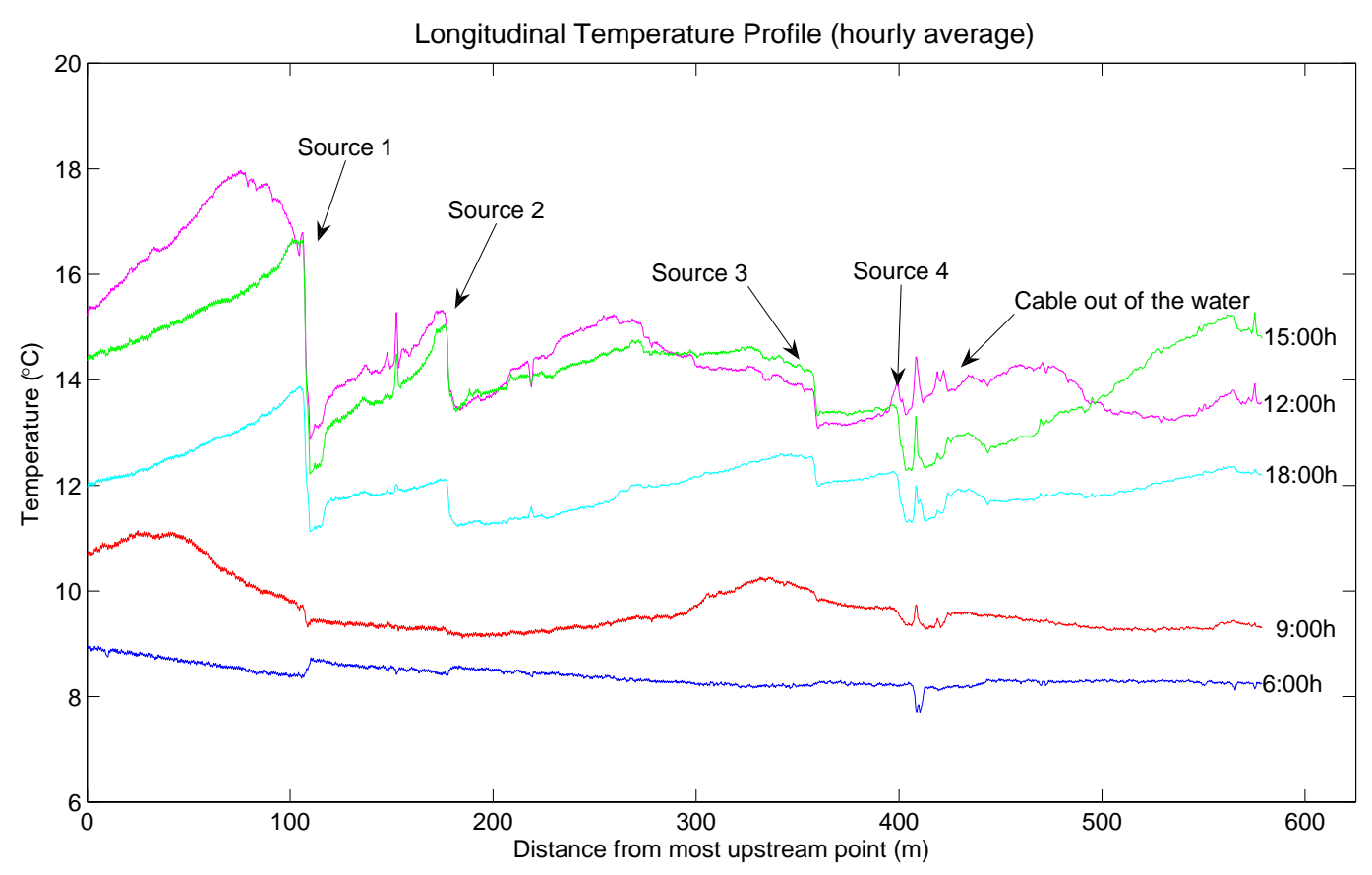

Fig. 3. Observed longitudinal temperature profile of the stream at different times at 26 April 2006. Clear temperature jumps can be seen at the points of a source. Short peaks are due to the fact that the cable is out of the water for a short distance.

is a source of energy. The longwave atmospheric radiation and the back radiation are both large, but they are also rather constant over time, and opposite in sign, so they do not cause large changes in temperature. The latent heat flux is significant when it is sunny, and it is small both during the night and when it is cloudy.

\section{Discussion}

The modeled stream temperature dynamics reflect the observed patterns, especially for the first 3 days. One apparent systematic error is that the model too quickly cools the water at the end of the day. This may be due to several reasons. The riverbed conduction is an important flux in the cooling down period: during the day the riverbed warms up and gives its energy back to the water when the stream cools. Three out of the four calibration constants $\left(D_{f}, D_{\text {diffuse }}\right.$ and $\left.d_{\text {soil }}\right)$ influence this flux, of which $D_{f}$ is the most sensitive (Table 1). The sensitivity of $d_{\text {soil }}$ is smaller, but the uncertainty is larger. With a decrease in the soil depth of more than $50 \%$ $\left(d_{\text {soil }}=0.0356 \mathrm{~m}\right)$, the RMSE decreases just over $10 \%$.

The latent heat flux plays an important role in the cooling. Because latent heat is a negative flux, and solar and longwave radiation influence this flux, over-estimation of solar and longwave radiation are compensated for over-estimation of the latent heat flux. The parameters defining solar and longwave radiation, influences the RMSE significantly (Ta- ble 1). The model is particularly sensitive to the Brunt coefficient and the "view to the sky" coefficient, with changes of $6.9 \%$ and $11.4 \%$ respectively in response to a $10 \%$ variation. The "view to the sky" coefficient has been taken constant along the stream. In reality this is not the case. However, we did not have more refined data available to improve this estimate. The high sensitivity to this parameter suggests that if this parameter is to be estimated better (by field observations), the model accuracy could improve significantly. The lack of accurate measurements of wind velocity also reduces model performance. Thus wind conditions should be measured to carry out a rigorous test of the model's predictive capabilities. During the observation the wind was observed to be essentially zero, which makes us believe that the influence of wind on evaporation was small in this case. With respect to model sensitivity, an increase in wind velocity of $1 \mathrm{~m} \mathrm{~s}^{-1}$ causes an increase in latent heat of $\mathrm{ca} 5 \mathrm{~W} \mathrm{~m}^{-2}$, which represents a sensitivity of 0.11 . We recognize that this term could become important under windy circumstances. Of the two meteorological parameters that were observed in a station outside the catchment (i.e. $T_{\text {air }}$ and $H$ ) the possible error on the RMSE is small, as can be judged from the sensitivities (i.e. 0.34 and 0.03 respectivily). However in future we shall use data from a new station to be installed in the catchment.

In the longitudinal profiles it can be seen that spatial fluctuations (especially, the gradual cooling down of the water) are often not matched in the model (Fig. 5b-d). Among other possibilities, these fluctuations may have been caused 
a

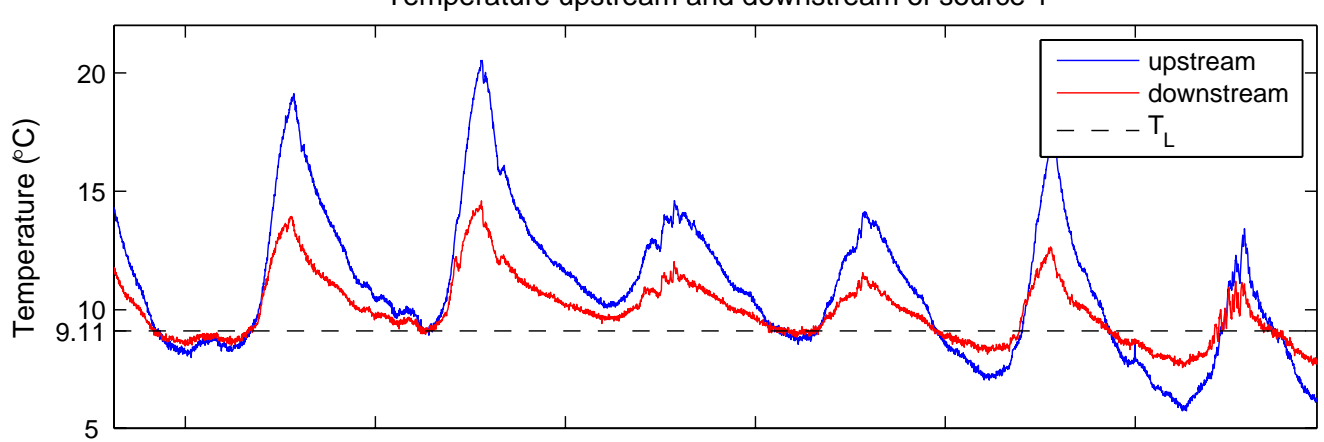

b

Temperature just upstream of source 1

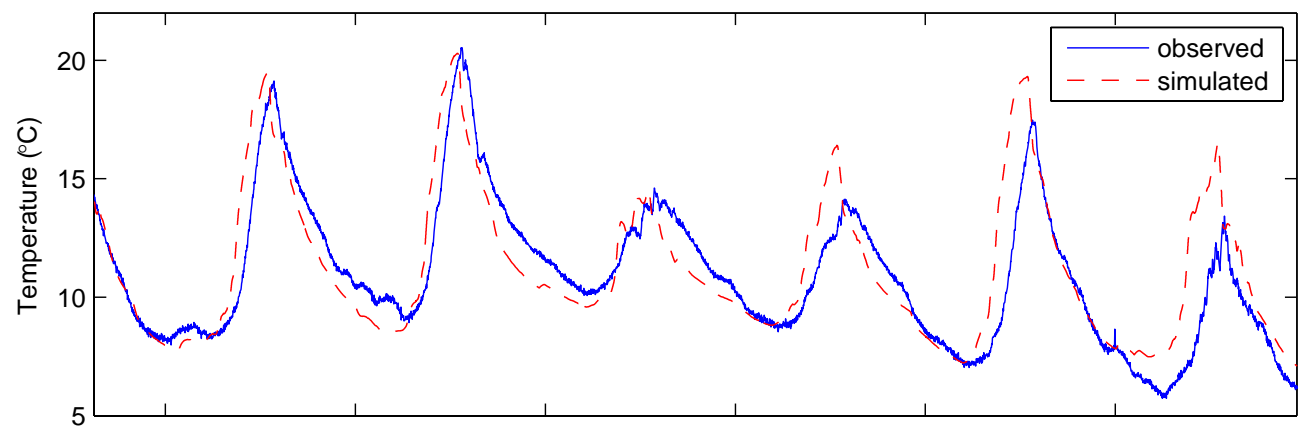

C

Temperature just downstream of source 1

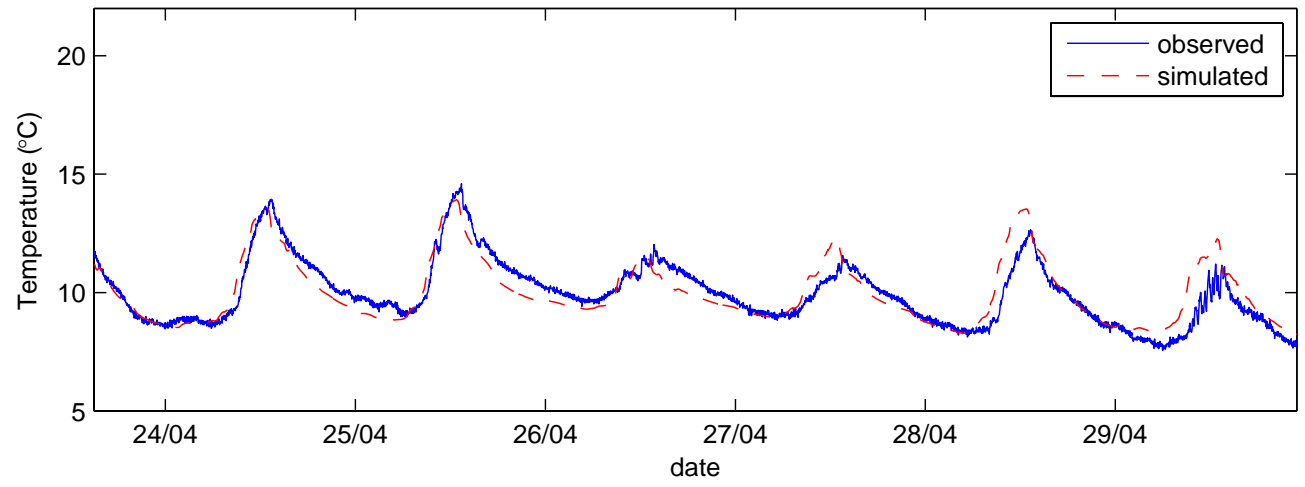

Fig. 4. Simulated and observed temperature of the investigated stream around source 1 (at $110 \mathrm{~m}$ from the most upstream point). (a) Observed temperature upstream and downstream of source 1. $T_{L}$ is the calculated temperature of the source, which is equal to the temperature where the upstream and downstream temperature curves intersect. (b) Observed and simulated temperature upstream of source 1. (c) Observed and simulated temperature downstream of source 1 .

by shading of vegetation or diffuse groundwater sources. The former influences the day-time heating of the water. Because the stream is so small, relatively small errors in vegetation height can result in large errors in the received solar radiation. This error would further increase the errors made in solar radiation measurements. The vegetation cover also influences the land cover longwave radiation via the "view to the sky" coefficient. The diffuse sources may have cooled the stream during the day since its temperature is lower than the stream temperature.

Another flux which has not been included in the model is the loss of water through infiltration. As presented by Selker et al. (2006b), there is evidence of diffuse infiltration. Since we have not accounted for this in our simulations, we predict 
Temperature at 23-Apr-2006 23:00:00

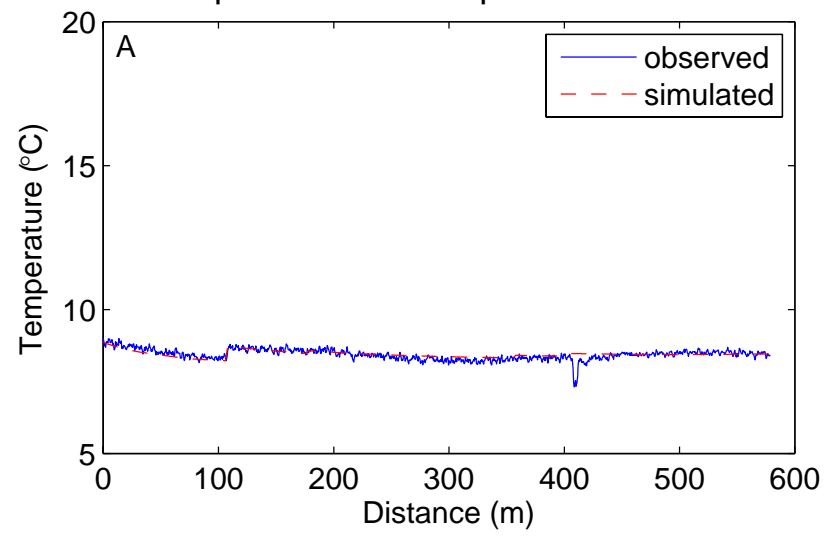

Temperature at 26-Apr-2006 10:20:00

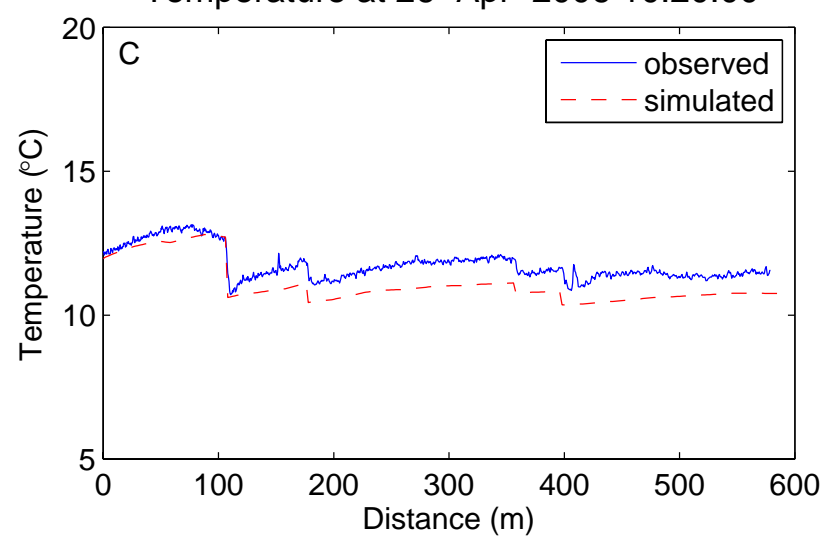

Temperature at 25-Apr-2006 11:00:00

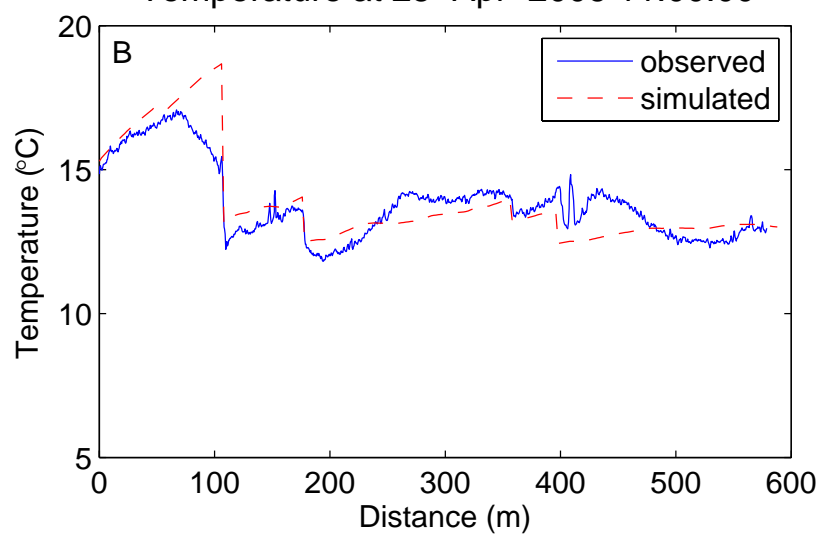

Temperature at 27-Apr-2006 14:30:00

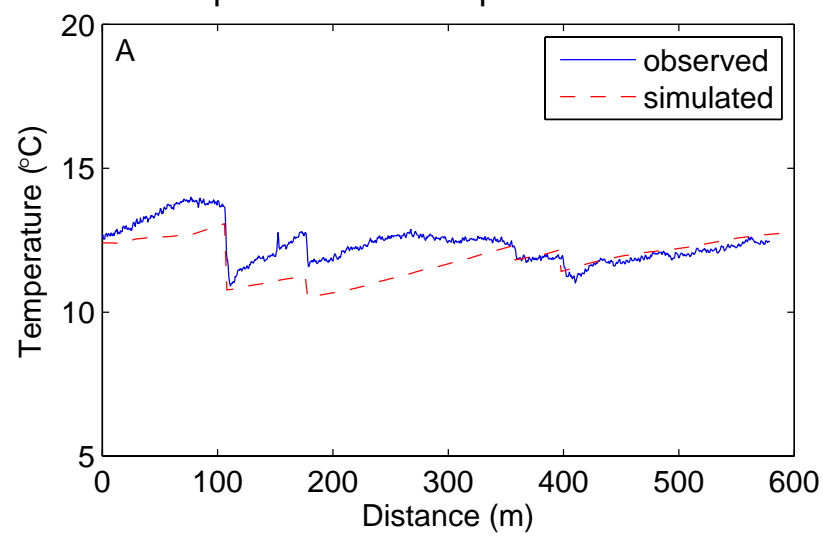

Fig. 5. Simulated and observed temperature profiles at four different moments in time.

an upstream discharge which is higher than that calculated as Q3 minus all sources. This would, in turn, influence the cross sectional area of the stream and thus, the depth. Using measurements from 2-5-2006 a net loss of $19 \%$ is calculated between Q3 (minus all sources) and Q4.

\section{Conclusions}

The goal of this work was to illustrate the utility of combining a high-resolution temperature measurement tool (DTS) with physically based thermal modeling to reveal stream dynamics. We present a stream temperature model that is based on identifiable physical processes controlling energy exchange and which includes lateral inflows as they are important fluxes in the stream considered. The model builds on earlier published conceptualizations, with several innovations to allow for more ready calibration and reduction of numerical artifacts. The model reproduces the spatial and temporal dynamics of stream temperature as recorded each meter along a first order stream using DTS measurement methods well, satisfying the major objectives of this study.
A key limitation of this study is the lack of independent shading and meteorological measurements adjacent to the stream. Without these measurements it is difficult to definitively validate the conceptualization of the stream system. With further refinement of the input data it is expected that hyporheic exchanges and even stream losses can be estimated through optimization of model-fit to the observed DTS data. In particular, the vegetation height and density should be determined with care, as it has a large influence on the received incoming radiation.

The DTS measuring technique allows comparison with the energy balance model at hundreds of points at over one thousand distinct time-intervals per day with approaching $0.01^{\circ} \mathrm{C}$ precision. This represents a remarkable advancement over the previous state of the art, comprised of a handful of point measurements typically with no better than $0.1^{\circ} \mathrm{C}$ precision. In future analyses the energy balance model will be used to test hypotheses on location and quantity of diffuse sources and sinks with the aim of hydrograph separation and identifying connectivity in runoff generation. Overall, we find that the DTS fiber optic offers new opportunities in the field 

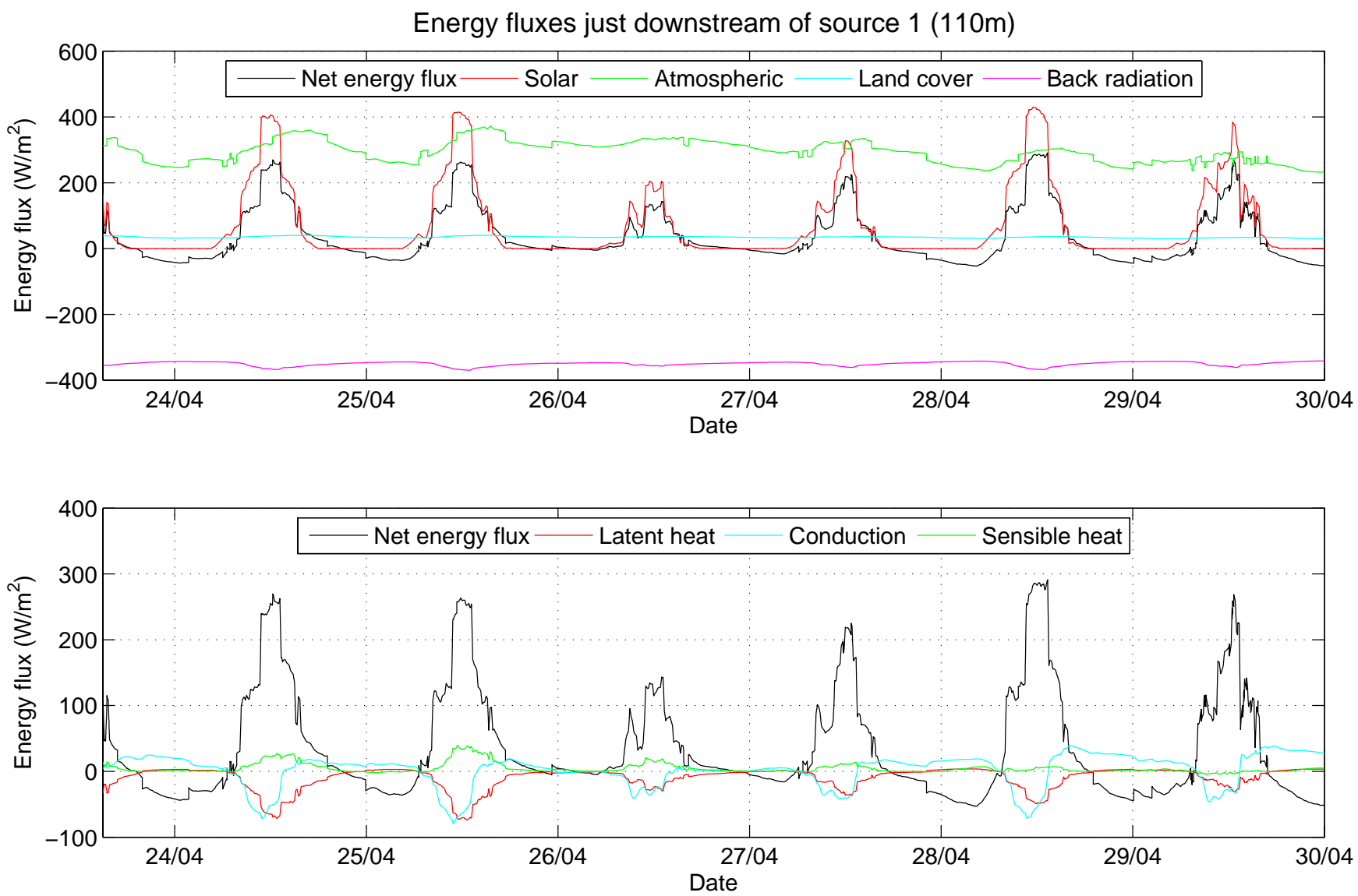

Fig. 6. Heat energy fluxes at source 1 .

of hydrology as an orthogonal source of information to constrain our conceptual models and thereby, advance understanding.

Acknowledgements. This research has been funded partly by the Delft Cluster project Veiligheid tegen overstromingen: CT04.30. The authors would like to thank the municipality of Ettelbruck for their cooperation and J. Friesen, J. Liebe, M. Poolman, M. Baptist, R. Schilperoort, E. Tromp, and B. Baartman for their support in the field. Additional support for J. S. Selker's participation was provided by the National Science Foundation under award 0447415. We thank the EPFL, the Swiss National Science Foundation (grants 109566 and 107910), the Oregon Experiment Station, the U.S. National Science Foundation (grant 0447415-EAR) for their financial support of this work.

\section{References}

Becker, M. W., Georgian, T., Ambrose, H., Siniscalchi, J., and Fredrick, K.: Estimating flow and flux of groundwater discharge using water temperature and velocity, J. Hydrol., 296, 221-233, 2004.
Boderie, P. and Dardengo, L.: Warmtelozing in oppervlaktewater en uitwisseling met de atmosfeer, Report Q3315, WL|Delft Hydraulics, 2003.

Boyd, M. and Kasper, B.: Analytical methods for dynamic open channel heat and mass transfer: methodology for the Heat Source Model Version 7.0, Watershed Sciences Inc., Portland, OR, USA, found at: http://www.heatsource.info/Heat_Source_v_7.0. pdf, 2003.

Brown, G. W.: Predicting temperature of small streams, Water Resour. Res., 5, 68-75, 1969.

Constantz, J.: Interaction between stream temperature, streamflow, and groundwater exchanges in alpine streams, Water Resour. Res., 34, 1609-1615, 1998.

Constantz, J., Cox, M. H., Sarma, L., and Mendez, G.: The Santa Clara River - The last natural river of Los Angeles. In Heat as a Tool for Studying the Movement of Ground Water Near Streams, edited by: Stonestrom D. A. and Constantz J., USGS Circular 1260, 21-27, USGS., 2003.

Dingman, S. L.: Physical Hydrology, 2nd ed., Prentice-Hall, Upper Saddle River, New Jersey 07458, 2002.

Evans, E. C., McGregor, G. R., and Petts, G. E.: River energy budgets with special reference to river bed processes, Hydrol. Processes, 12, 575-595, 1998.

Katsuyama, M., Ohte, N., and Kobashi, S.: A three-component 
end-member analysis of streamwater hydrochemistry in a small Japanese forested headwater catchment, Hydrol. Processes, 15, 249-260, 2001.

Kendall, C., McDonnell, J. J., and Gu, W.: A look inside "black box" hydrograph separation models: a study at the Hydrohill catchment, Hydrol. Processes, 15, 1877-1902, 2001.

Kobayashi, D.: Separation of the snowmelt hydrograph by stream temperatures, J. Hydrol., 76, 155-165, 1985.

Kobayashi, D., Ishii, Y., and Kodama, Y.: Stream temperature, specific conductance and runoff processes in mountain watersheds, Hydrol. Processes, 13, 865-876, 1999.

Lapham, W. W.: Use of temperature profiles beneath streams to determine rates of vertical ground-water flow and vertical hydraulic conductivity, U.S. Geol. Surv. Water Supply Paper 2337. U.S. Geol. Surv., 1989.

Monteith, J. L.: Evaporation and surface temperature, Quart. J. R. Meteorol. Soc., 107, 1-27, 1981.

Niswonger, R. G., Prudic, D. E., Pohll, G., and Constantz, J.: Incorporating seepage losses into the unsteady streamflow equations for simulating intermittent flow along mountain front streams, Water Resour. Res., 41, W06006, doi:10.1029/2004WR003677, 2005.

Seibert, J. and McDonnell, J. J.: On the dialog between experimentalist and modeler in catchment hydrology: use of soft data for multi-criteria model calibration, Water Resour. Res., 38, 12311241, 2002.

Selker, J. S., Thévenaz, L., Huwald, H., Mallet, A., Luxemburg, W., Van de Giesen, N., Stejskal, M., Zeman, J., Westhoff, M., and Parlange, M. B.: Distributed fiber optic temperature sensing for hydrologic systems, Water Resour. Res., 42, W12202, doi:10.1029/2006WR005326, 2006a.

Selker, J. S., Van de Giesen, N., Westhoff, M. C., Luxemburg, W., and Parlange, M.: Fiber optics opens window on stream dynamics, Geophys. Res. Lett., 33, L24401, doi:10.1029/2006GL027979, 2006b.
Shanley, J. B. and Peters, N. E.: Preliminary observations of streamflow generation during storms in a forested Piedmont watershed using temperature as a tracer, J. Contam. Hydrol., 3, 349-365, 1988.

Shi, Y., Allis, R., and Davey, F.: Thermal modeling of the southern Alps, New Zealand, Pure appl, Geophys., 146, 469-501, doi:10.1007/BF00874730, 1996.

Silliman, S. E., Ramirez, J. and McCabe, R. L.: Quantifying downflow through creek sediments using temperature time series: onedimensional solution incorporating measured surface temperature, J. Hydrol., 167, 99-119, 1995.

Sklash, M. G. and Farvolden, R. N.: The role of groundwater in storm runoff, J. Hydrol., 43, 45-65, 1979.

Stallman, R. W.: Steady one-dimensional fluid flow in a semiinfinite porous medium with sinusoidal surface temperature, J. Geophys. Res., 70, 2821-2827, 1965.

Uhlenbrook, S. and Hoeg, S.: Quantifying uncertainties in tracerbased hydrograph separations: a case study for two-, three- and five-component hydrograph separations in a mountainous catchment, Hydrol. Processes, 17, 431-453, 2003.

Uhlenbrook, S. and Leibundgut, C.: Process-oriented catchment modelling and multiple-response validation, Hydrol. Processes, 16, 423-440, 2002.

Van Leer, B.: Towards the ultimate conservative difference scheme II. Monotonicity and conservation combined in a second order scheme, J. Comput. Phys., 14, 361-370, 1974.

Webb, B. W. and Zhang, Y.: Spatial and seasonal variability in the components of the River heat budget, Hydrol. Processes, 11, 79$101,1997$.

Wenninger, J., Uhlenbrook, S., Tilch, N., and Leibundgut, C.: Experimental evidence of fast groundwater responses in a hillslope/floodplain area in the Black Forest Mountains, Germany, Hydrol. Processes, 18, 3305-3322, 2004.

Williams, B.: Hydrobiological modeling, University of Newcastle, NSW, Australia: http://www.lulu.com, 2006. 